\title{
Gender difference of tooth brushing motion and force on self-brushing and caregivers' brushing in dental professionals
}

\author{
Mika Hanasaki ${ }^{1}$, Kuniko Nakakura-Ohshima ${ }^{2 *}$, Tsutomu Nakajima ${ }^{2}$, Yukiko Nogami ${ }^{2}$ and Haruaki Hayasaki ${ }^{2}$ \\ ${ }^{1}$ Ishitani Clinic of Pedodontics and Orthodontics, 41-4, Miyajimacho, Aira, Kagoshima, 899-5432, Japan \\ ${ }^{2}$ Department of Pediatric Dentistry, Graduate School of Medical and Dental Sciences, Niigata University, 2-5274, Gakkocho-dori, Chuo-ku, Niigata, 951-8514, Japan
}

\begin{abstract}
While the need for caregivers' brushing have increased, the appropriate brushing motion is still unclear. The aim of this study was to clarify the gender difference of brushing motions between self-brushing and caregivers' brushing.

Tooth brushing motions of 15 male and 20 female dental professionals were analyzed using a three-dimensional accelerometer and a strain tension gage. They brushed the buccal surfaces of the right lower molars using two brushing situations. Multilevel model analysis was applied in this study.

Concerning self-brushing, gender difference was significant in cycle duration, buccal-lingual motion and brushing force, whereas for caregivers'brushing, a significant difference was observed only in the brushing force. In addition, the brushing force during caregivers' brushing was significantly greater than that of self-brushing on both genders.

This study clearly demonstrated gender difference of brushing motion and force. Furthermore, a significant difference between self-brushing and caregivers' brushing was also evident. These results might contribute to improving the caregivers' brushing.
\end{abstract}

\section{Introduction}

Meticulous plaque removal on a daily basis is important to prevent caries and gingival and periodontal diseases [1]. Various methods are employed to maintain oral hygiene, of which the most common is tooth brushing. And also, it is obvious that manual dexterity and motivation of an individual are of paramount importance in oral hygiene [2]. Some differences in the oral health habits of male and female were reported [3-4l, females have 'healthier' behavior than males in terms of tooth brushing frequency, dental floss and interdental brush usages. These studies showed that females are more aware of oral hygiene and also more motivated, however it is unclear whether there is gender difference in the skill of tooth brushing.

Recently, several studies have tried to evaluate brushing motion three-dimensionally [5-9]. Tosaka, et al. [6] demonstrated characteristics of tooth brushing motion and brushing force using a three-dimensional (3-D) accelerometer and a strain tension gage. Inada, et al. [10] evaluated toothbrush and arm-joint motion during tooth brushing using a motion capture system. These two studies used female dental hygienists as professional tooth brushers to standardize as much as possible the brushing conditions. Regardless of these studies so far, the appropriate tooth brushing motion remains unclear, and gender difference is further unknown.

Daily oral hygiene presents challenges to people with disabilities who are unable to perform preventive at-home oral care themselves and rely on caregivers [11]. Caregivers play a vital role also in infants
[12], children with disabilities [13,14], and elderly people $[15,16]$. Although nursing staffs are generally interested in improving the oral care of their caretakers, it has been recognized that their knowledge in this area is often inadequate. Some caregivers of housebound patients in particular are without any training in oral care. Accordingly, many studies have reported poor oral hygiene in those dependent people [17]. Evidence-based oral hygiene education seems to be a feasible way to increase the motivation for daily oral care tasks among caregivers, and thus improve the oral hygiene status among the caretakers $[18,19]$. In addition, oral hygiene education is not only the transfer of knowledge, but also must take into consideration personal habits and skills [20]. However, reports on caregivers' brushing motion have been limited so far. In particular, to our knowledge, the analysis of gender difference has never been previously reported.

Accordingly, the aim of this study was to clarify the difference of brushing motion, including force, between self-brushing and caregivers' brushing focusing on the gender difference.

${ }^{\star}$ Correspondence to: Kuniko Nakakura-Ohshima, Department of Pediatric Dentistry, Graduate School of Medical and Dental Science, Niigata University, 2-5274, Gakkocho-dori, Chuo-ku, Niigata, 9518514, Japan, Tel/Fax: +81 25-2272910; E-mail: ohshima@dent.niigata-u.ac.jp

Key words: gender, tooth brushing, caregiver, motion, force

Received: March 08, 2018; Accepted: March 28, 2018; Published: March 31, 2018 


\section{Materials and methods}

\section{Study population}

The participants in this study were 15 male and 20 female righthanded dentists and dental hygienists. All participants belonged to the Niigata University Medical and Dental Hospital. To research the typical brushing motions of self-brushing and caregivers' brushing, professional tooth brushers who perform caregivers' brushing as daily work were selected as participants.

The exclusion criteria were missing tooth or active periodontitis on the right lower molar region, oral removable or fixed prostheses or orthodontic appliances. Subjects' average age was 37 years and 1 month (standard deviation (SD) 0.6) for male and 36 years old (SD 0.4) for female, respectively. All participants were given oral and written information about the purpose and detailed procedures of the study and gave informed consent before participating in the study. The study protocol received approval from the Ethical Committee of the Faculty of Dentistry, Niigata University (25-R23-10-04).

\section{Study design and procedures}

The Butler GUM 211 manual toothbrush (Sunstar Butler ${ }^{\circledR}$, Osaka, Japan), approved by the American Dental Association, was used in this study. We used the method of Tosaka, et al. [6]. A wired accelerometer (MP-M606/400B, MicroStone Inc., Saku City, Nagano prefecture, Japan) was attached to the tail of the toothbrush, and a strain tension gage (KFG-C15, KYOWA ${ }^{\circ}$ Inc., Tokyo, Japan) was adhered on the neck of the toothbrush (Figure 1). The strain gage attached to each toothbrush was calibrated at $300 \mathrm{~g}$ weight individually in advance. Measuring errors of both devices were at most $\pm 2 \%$ of the measuring range in bench tests. The weight of each sensor was $8 \mathrm{~g}$ and $0.5 \mathrm{~g}$, respectively.

Because the coordinate system was defined by the direction of the accelerometer attached to the toothbrush, (1) the $\mathrm{X}$-axis was along the tooth brushing axis (i.e. the anterior-posterior direction), (2) the $\mathrm{Y}$-axis was perpendicular to the $\mathrm{X}$-axis (i.e., in a superior-inferior direction), and (3) the Z-axis was perpendicular to the $\mathrm{X}-\mathrm{Y}$ plane (i.e., in a buccallingual direction) (Figure 1).

An instructed task for each participant was to brush the buccal surfaces of the right lower four teeth; the first and second premolars and the first and second molars. They brushed these teeth in two situations: (1) brushing their own teeth by themselves, and (2) brushing artificial teeth (NISSIN DENTAL PRODUCTS INC., Kyoto, Japan) attached to a dental mannequin (Trunk Unit Set, NISSIN DENTAL PRODUCTS INC., Kyoto, Japan) simulated caregivers' brushing. In the latter, a mannequin laid on a dental chair in the supine position (Figure 2). Prior to the experiment, subjects were allowed to brush the model teeth once on the mannequin to become accustomed to the experimental conditions. Each surface was brushed for 10 seconds and no other instructions on brushing technique were given to each subject.

\section{Data analysis}

Displacements (i.e., changing position of the accelerometer) and brushing force were sampled at $100 \mathrm{~Hz}(1 / 0.01 \mathrm{~s})$, and the resulting data were stored in a text file on a Windows ${ }^{\circ}$ PC. Displacement was converted from acceleration by integration by using the software (MVP-VD-S, MicroStone Inc., Saku City, Nagano Prefecture, Japan).

Because the motion of the toothbrush was a series of repeated cyclic movement, the changes of each 3-D displacement and the brushing force can be plotted simultaneously as shown in Figure 3.

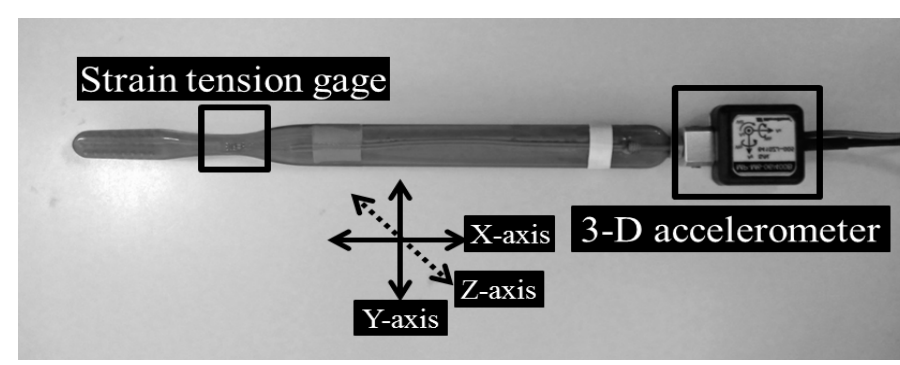

Figure 1. An accelerometer and a strain tension gage were attached to the tail of the handle and to the neck of the toothbrushes, respectively. Arrows indicate motion along the $\mathrm{X}$-, $\mathrm{Y}$ - and Z-axes.
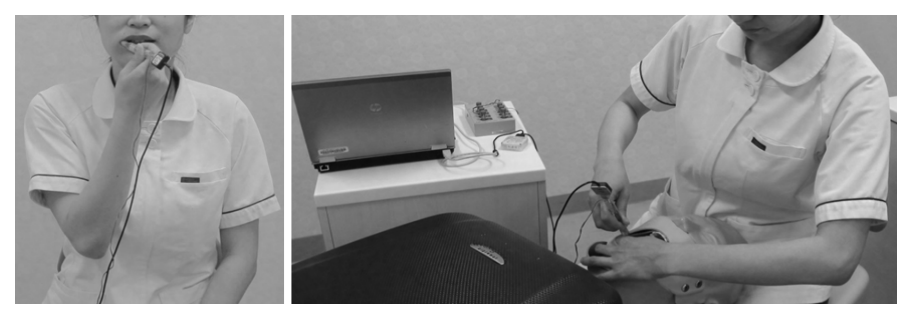

Figure 2. Measurement scenery of two experiment; self-brushing and caregivers' brushing.

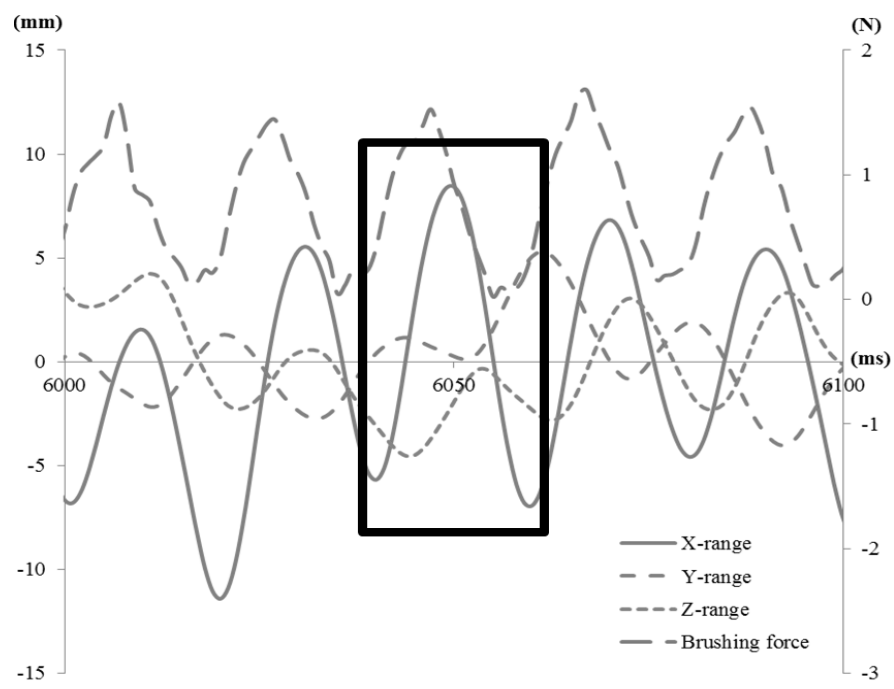

Figure 3. An example of displacements along the X-, Y-, Z-axes and brushing force $(\times 10)$ plotted simultaneously. An entire motion sequence can be divided into component cycles based on the $\mathrm{X}$-axis motion, which is twice as great as or more than the motion along the $\mathrm{Y}$ - and $\mathrm{Z}$-axes.

In these series of movements, the time from the minimum position to the next minimum position through the maximum position was defined as one cycle (Figure 4). We chose the representative 10 cycles best expressing characteristics of each participant to reduce between cycle random variability using the method by Tosaka, et al. [6]. We analyzed (1) cycle duration (a time for a stroke), (2) X-, Y-, Z-range (distance of toothbrush motion that was the difference between maximum and minimum values) and 3D-range that unified each direction and (3) mean brushing force.

\section{Statistical analysis}

The data were evaluated using multilevel linear statistical models with MLwiN software (ver. 2.24, Centre for Multilevel Modeling, University of Bristol, England). A two-level model, with variation hierarchically partitioned (1) between subjects (or individuals) and (2) between cycles, was used to evaluate systematic differences in durations, 
displacements, and brushing force. Each analysis was carried out based on 35 subjects, with two brushings, ten best cycles, for a total of 700 cycles.

\section{Results}

Table 1 shows the comparison of cycle duration, X-, Y-, Z-, 3-D ranges and mean brushing force between male and female on selfbrushing and caregivers' brushing, respectively.

In self-brushing, cycle duration and Z-range of males $(183.27 \mathrm{msec}$, $4.66 \mathrm{~mm})$ were significantly shorter than those of females $(206.00 \mathrm{msec}$, $6.17 \mathrm{~mm})$. On the other hand, the mean brushing force of males $(1.85 \mathrm{~N})$ was significantly greater than that of females $(1.32 \mathrm{~N})$.

As for caregivers' brushing, significant difference of mean brushing force between males $(2.53 \mathrm{~N})$ and females $(1.68 \mathrm{~N})$ was also recognized. On the other hand, there was no significant difference of duration and X-, Y-, Z-, 3D-ranges between males and females.
The comparison of variables between self-brushing and caregivers' brushing is shown in Table 2. For male, Y- and Z-range of caregivers' brushing were significantly larger than those of self-brushing, and also the brushing force of the caregivers' was significantly greater than that of self-brushing. For female, significant difference was recognized in cycle duration in addition to these.

Tables 3 and 4 show between-subjects and between-cycles variances of tooth brushing variables. Most of between-subjects variances were larger than between-cycles variances in both males and females during self-brushing (Table 3). However, in the caregivers' brushing (Table 4), between-cycle variance of cycle duration was larger than betweensubject variance in both males and females.

Table 5 shows the intra-individual correlations between selfbrushing and caregivers' brushing. Males had a significant correlation only on X-range, and females showed significant correlations on all variables except $\mathrm{Y}$-range.

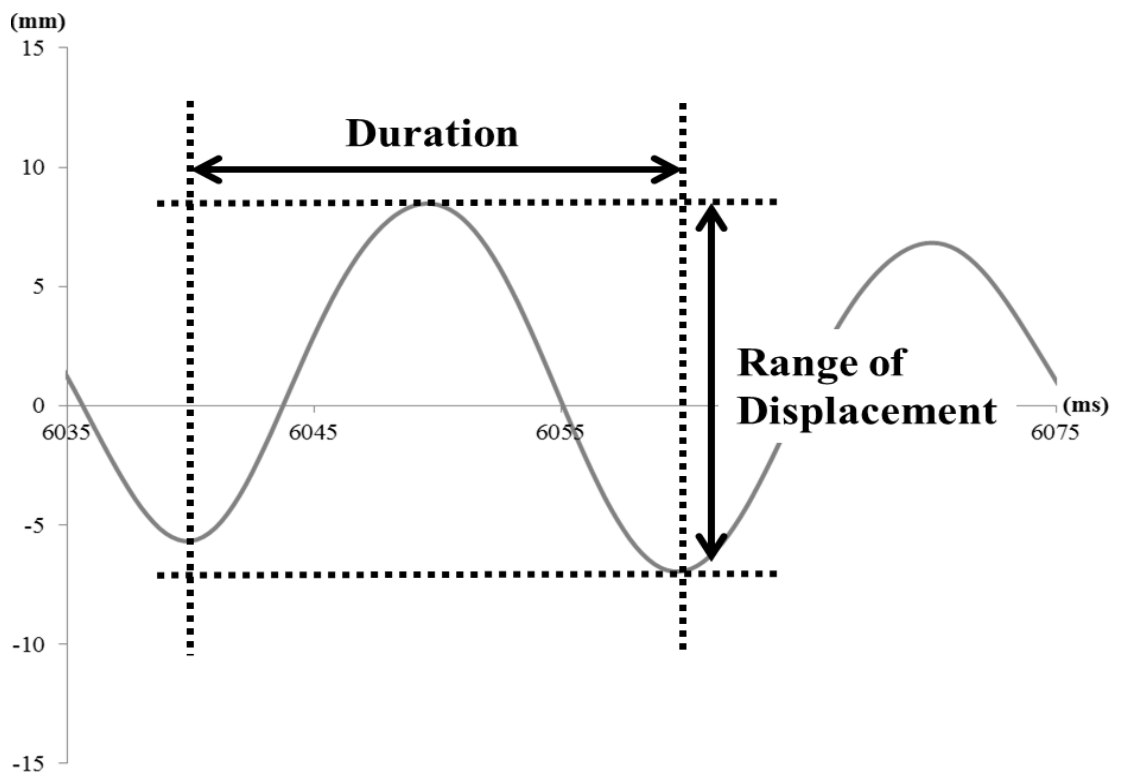

Figure 4. An example of a single tooth brushing cycle of X-axis from Figure 3. Cycle duration and range of displacement are shown.

Table 1. Comparison of variables between male and female.

\begin{tabular}{|c|c|c|c|c|c|c|}
\hline \multirow[t]{3}{*}{ Measures } & \multicolumn{6}{|c|}{ Self-brushing } \\
\hline & \multicolumn{2}{|c|}{ Male } & \multicolumn{2}{|c|}{ Female } & \multicolumn{2}{|c|}{ Difference } \\
\hline & Mean & S.E. & Mean & S.E. & Mean & S.E. \\
\hline Cycle duration [msec] & 183.27 & 9.32 & 206.00 & 6.71 & 22.73 & $10.25^{*}$ \\
\hline $\mathrm{X}$-range $[\mathrm{mm}]$ & 14.40 & 1.85 & 15.83 & 1.41 & 1.43 & 2.15 \\
\hline Y-range $[\mathrm{mm}]$ & 4.54 & 0.43 & 6.03 & 0.58 & 1.49 & 0.89 \\
\hline Z-range $[\mathrm{mm}]$ & 4.66 & 0.35 & 6.17 & 0.46 & 1.51 & $0.71^{*}$ \\
\hline 3D-range $[\mathrm{mm}]$ & 16.23 & 1.82 & 18.56 & 1.48 & 2.33 & 2.26 \\
\hline Brushing force $[\mathrm{N}]$ & 1.85 & 0.21 & 1.32 & 0.15 & -0.53 & $0.22 *$ \\
\hline \multirow[t]{3}{*}{ Measures } & \multicolumn{6}{|c|}{ Caregivers' brushing } \\
\hline & \multicolumn{2}{|c|}{ Male } & \multicolumn{2}{|c|}{ Female } & \multicolumn{2}{|c|}{ Difference } \\
\hline & Mean & S.E. & Mean & S.E. & Mean & S.E. \\
\hline Cycle duration [msec] & 188.87 & 3.93 & 189.70 & 4.11 & 0.83 & 6.28 \\
\hline X-range $[\mathrm{mm}]$ & 14.25 & 0.98 & 13.91 & 0.91 & 0.34 & 1.39 \\
\hline Y-range $[\mathrm{mm}]$ & 7.89 & 0.77 & 10.20 & 0.79 & 2.31 & 1.21 \\
\hline Z-range [mm] & 12.05 & 1.10 & 11.41 & 1.09 & 0.65 & 1.67 \\
\hline 3D-range [mm] & 20.82 & 1.42 & 21.70 & 1.31 & 0.89 & 2.00 \\
\hline Brushing force $[\mathrm{N}]$ & 2.53 & 0.17 & 1.68 & 0.14 & -0.85 & $0.22 * *$ \\
\hline
\end{tabular}

S.E. standard error of the mean

${ }^{*} p<0.05,{ }^{*} p<0.01$ 
Table 2. Comparison of variables between self- brushing and caregivers' brushing.

\begin{tabular}{|c|c|c|c|c|c|c|}
\hline \multirow[t]{3}{*}{ Measures } & \multicolumn{6}{|c|}{ Male } \\
\hline & \multicolumn{2}{|c|}{ Self-brushing } & \multicolumn{2}{|c|}{ Caregivers' brushing } & \multicolumn{2}{|c|}{ Difference } \\
\hline & Mean & S.E. & Mean & S.E. & Mean & S.E. \\
\hline Cycle duration [msec] & 183.27 & 7.16 & 188.87 & 3.93 & 5.60 & 10.12 \\
\hline X-range $[\mathrm{mm}]$ & 14.40 & 1.48 & 14.25 & 0.98 & -0.16 & 2.09 \\
\hline Y-range $[\mathrm{mm}]$ & 4.54 & 0.63 & 7.89 & 0.77 & 3.35 & $0.89 * *$ \\
\hline Z-range $[\mathrm{mm}]$ & 4.66 & 0.81 & 12.05 & 1.10 & 7.40 & $1.15^{* *}$ \\
\hline 3D-range $[\mathrm{mm}]$ & 16.23 & 1.63 & 20.82 & 1.42 & 4.58 & 2.31 \\
\hline Brushing force $[\mathrm{N}]$ & 1.85 & 0.19 & 2.53 & 0.17 & 0.68 & $0.27^{*}$ \\
\hline \multirow[t]{3}{*}{ Measures } & \multicolumn{6}{|c|}{ Female } \\
\hline & \multicolumn{2}{|c|}{ Self-brushing } & \multicolumn{2}{|c|}{ Caregivers' brushing } & \multicolumn{2}{|c|}{ Difference } \\
\hline & Mean & S.E. & Mean & S.E. & Mean & S.E. \\
\hline Cycle duration [msec] & 206.00 & 5.03 & 189.70 & 4.57 & -16.30 & $7.12 *$ \\
\hline X-range $[\mathrm{mm}]$ & 15.83 & 1.11 & 13.91 & 0.95 & -1.92 & 1.57 \\
\hline $\mathrm{Y}$-range $[\mathrm{mm}]$ & 6.03 & 0.79 & 10.20 & 0.87 & 4.18 & $1.11^{* *}$ \\
\hline Z-range $[\mathrm{mm}]$ & 6.17 & 0.93 & 11.41 & 1.19 & 5.24 & $1.31 * *$ \\
\hline 3D-range [mm] & 18.56 & 1.39 & 21.70 & 1.37 & 3.14 & 1.96 \\
\hline Brushing force $[\mathrm{N}]$ & 1.32 & 0.11 & 1.68 & 0.10 & 0.35 & $0.18^{*}$ \\
\hline
\end{tabular}

S.E. standard error of the mean

$* p<0.05, * * p<0.01$

Table 3. Between-subjects and between-cycles variances for self-brushing.

\begin{tabular}{|c|c|c|c|c|}
\hline \multirow[t]{3}{*}{ Measures } & \multicolumn{4}{|c|}{ Male } \\
\hline & \multicolumn{2}{|c|}{ Between-subjects } & \multicolumn{2}{|c|}{ Between-cycles } \\
\hline & Estimate & S.E. & Estimate & S.E. \\
\hline Cycle duration & 1283.10 & 476.04 & 205.56 & 25.02 \\
\hline X-range & 50.81 & 18.64 & 2.45 & 0.30 \\
\hline Y-range & 2.30 & 1.03 & 5.32 & 0.65 \\
\hline Z-range & 1.61 & 0.68 & 2.57 & 0.31 \\
\hline 3D-range & 49.63 & 18.18 & 1.63 & 0.20 \\
\hline Brushing force & 0.67 & 0.25 & 0.10 & 0.01 \\
\hline \multirow[t]{3}{*}{ Measures } & \multicolumn{4}{|c|}{ Female } \\
\hline & \multicolumn{2}{|c|}{ Between-subjects } & \multicolumn{2}{|c|}{ Between-cycles } \\
\hline & Estimate & S.E. & Estimate & S.E. \\
\hline Cycle duration & 582.89 & 188.67 & 137.11 & 14.45 \\
\hline X-range & 30.73 & 9.89 & 5.17 & 0.55 \\
\hline Y-range & 9.17 & 3.05 & 4.77 & 0.50 \\
\hline Z-range & 5.33 & 1.92 & 7.27 & 0.77 \\
\hline 3D-range & 39.15 & 12.50 & 3.81 & 0.40 \\
\hline Brushing force & 0.24 & 0.08 & 0.07 & 0.01 \\
\hline
\end{tabular}

S.E. standard error of the mean

Table 4. Between-subjects and between-cycles variances for caregivers' brushing.

\begin{tabular}{|c|c|c|c|c|}
\hline \multirow[t]{3}{*}{ Measures } & \multicolumn{4}{|c|}{ Male } \\
\hline & \multicolumn{2}{|c|}{ Between-subjects } & \multicolumn{2}{|c|}{ Between-cycles } \\
\hline & Estimate & S.E. & Estimate & S.E. \\
\hline Cycle duration & 113.23 & 85.98 & 1188.82 & 144.70 \\
\hline X-range & 13.99 & 5.24 & 3.67 & 0.45 \\
\hline Y-range & 8.29 & 3.28 & 6.79 & 0.83 \\
\hline Z-range & 17.32 & 6.56 & 6.50 & 0.79 \\
\hline 3D-range & 29.85 & 11.04 & 3.89 & 0.47 \\
\hline Brushing force & 0.42 & 0.16 & 0.12 & 0.01 \\
\hline \multirow[t]{3}{*}{ Measures } & \multicolumn{4}{|c|}{ Female } \\
\hline & \multicolumn{2}{|c|}{ Between-subjects } & \multicolumn{2}{|c|}{ Between-cycles } \\
\hline & Estimate & S.E. & Estimate & S.E. \\
\hline Cycle duration & 368.35 & 131.87 & 483.56 & 50.97 \\
\hline X-range & 17.46 & 5.71 & 5.91 & 0.62 \\
\hline Y-range & 13.76 & 4.78 & 13.43 & 1.42 \\
\hline Z-range & 21.15 & 8.90 & 9.87 & 1.04 \\
\hline 3D-range & 36.67 & 11.84 & 7.54 & 0.80 \\
\hline Brushing force & 0.36 & 0.12 & 0.16 & 0.02 \\
\hline
\end{tabular}

S.E. standard error of the mean 
Table 5. Intra-individual correlations between self and caregivers' brushing.

\begin{tabular}{|c|c|c|}
\hline & Male & Female \\
\hline Cycle duration & -0.15 & $0.59^{*}$ \\
\hline X-range & $0.63^{*}$ & $0.70^{*}$ \\
\hline Y-range & 0.41 & 0.34 \\
\hline Z-range & -0.15 & $0.75^{*}$ \\
\hline 3D-range & 0.42 & $0.62^{*}$ \\
\hline Brushing force & 0.20 & $0.72^{*}$ \\
\hline
\end{tabular}

\section{Discussion}

Controlling dental plaque is the most important way of preventing dental disease, and one of the most principal and effective methods of plaque control is tooth brushing [5]. Achieving an optimal result depends on the individual motivation and manual skills, as well as on the complexity of the dentition. Although the individual oral condition makes plaque elimination difficult, good technique for tooth brushing is regarded as necessary.

Several studies $[3,4]$ reported gender difference of health habits including oral hygiene. Kawamura, et al. [4] showed that females have better oral hygiene practices, whereas males have unpleasant subjective symptoms such as tooth mobility. However, there is no article that confirmed gender differences regarding the skill of tooth brushing.

In recent years, the demand for caregivers' brushing has increased, and the subjects of this brushing are diverse, including people with disabilities, children and elderly people. It is now well-known that poor oral hygiene has been linked to increased risk for serious medical problems, including pulmonary infection, cardiovascular disease, stroke, brain abscess, and poor control of diabetes mellitus [21]. Several articles have pointed out that oral care should be included in nursing work as a more highly prioritized task [22-24], however, the caregivers' brushing technique is demanded not only to professional medical staff such as nurses but also facility staff or family members engaging in home healthcare because the number of targeted people are increasing recently. It means that both males and females need to carry out caregivers' brushing. However, appropriate caregivers' brushing motion has not been clarified.

Therefore, in this study, we examined the differences between male and female of two exercises; self-brushing and caregivers' brushing.

This study demonstrated that no gender difference of tooth brushing motion was recognized in both self-brushing and caregivers' brushing, except cycle duration and Z- range in self-brushing. Especially in caregivers' brushing, 3-D motion of tooth brushing was approximately similar between male and female dental experts. It was shown that caregivers' brushing was well-trained and had a uniformed motion for dental professionals who performed it in their daily work.

On the other hand, the brushing force of males was larger than that of females in both self-brushing and caregivers' brushing. In addition, the brushing force of the caregivers' brushing was larger than that of self-brushing in both males and females.

Walking, running, and cycling are common voluntary human rhythmic movement. Due to the anthropometric differences between males and females, significant sex differences in gaits during normal walking have been reported [25]. Recently, with the computational three-dimensional gait analyses, several reports have identified gender differences in the kinematic and kinetic data of the trunk, hip, knee and ankle joints [26]. As for the tooth brushing, Inada, et al. [10] reported that all arm joints moved synchronously, and tooth brushing motion was controlled by coordinated movement of the joints. Therefore, since tooth brushing is also a cyclic motion in which joints form rhythms, there is a possibility that gender difference may occur in the cycle duration of tooth brushing.

The tooth brushing forces with a manual toothbrush have been reported with wide range (1.6N-318g) in many studies [27-29]. However, gender differences of brushing force has been controversially discussed. Annette, et al. [27] reported gender differences of brushing force was not statistically recognized. By contrast, Ganns, et al. [20] reported the only significant gender difference was in brushing force, which was slightly higher in males. In this study, the mean brushing force of self-brushing was $1.85 \mathrm{~N}$ in males and $1.32 \mathrm{~N}$ in females. Both variables in the present study were within the ranges previously reported, but it is noteworthy that brushing force of males was 1.5 times greater than that of females. Regarding the tooth brushing force, gender differences were recognized even in the dental professionals.

Tooth brushing is a factor in the etiology of gingival recession and dental abrasion, and several studies reported the correlation between force and gingival recession. Burgett, et al. [29] described that subjects with wedge-shaped lesions had significantly higher mean brushing force than subjects without cervical wear $(2.9$ versus $2.1 \mathrm{~N})$. From these studies it has been recommended that tooth brushing force should not exceed 3N [20]. Akgul, et al. [30] stated the prevalence of tooth brushing abrasions was seen more frequently in males than in females. This doesn't contradict the result of this study that brushing force of males was higher than that of females. However, Sadaf, et al. [31] stated gender differences regarding presence of non-carious cervical lesions was not significant. The effect of other factors influencing abrasion or gingival recession, such as toothbrush form, the toughness of bristles, the frequency of brushing and the brushing technique, couldn't be ignored.

Caregivers' brushing force was also larger than self-brushing in this study. Uenoyama, et al. [32] examined the relationship between brushing movements and oral sensory perception, and mentioned the following. When sensory perception in the oral cavity was blocked, the rhythmical pattern of brushing motion and muscle activity was lost, and brushing power was greater than in the case without blocking. From that result, it was suggested that the brushing force was controlled by the feedback from the oral sensory perception. Thus, that might be one of the reasons that brushing force of caregivers' brushing was larger than self-brushing in this study. Furthermore, this study showed Y- and Z-range of caregivers' brushing was larger than that of self-brushing. The reason might be that in caregivers' brushing, dental professionals make more complicated movement by looking at the teeth. Alternatively, brushing posture of caregivers' brushing might allow for more freedom of motion, however, further research is required. Caregivers should control the brushing from the feeling of their arm or fingers and the facial expressions of a person to be brushed. Excessive force or motion causes pain and leads to the latter uncooperative and resistant to oral care.

In self-brushing, between-subject variances were bigger than between-cycle variances for most measures, thus the existence of a personal characteristic cyclic pattern was suggested. In contrast, in caregivers' brushing, between-cycles variance of cycle duration was greater than between-subject variance in both male and female. Inada, et al. [8] described that the shoulder and wrist control the hand motion, whereas the elbow generates the cyclic rhythm during tooth brushing. 
In caregivers' brushing, the posture of caregiver was very different from that in self-brushing, so there is a possibility that the angle of the elbow may be hard to make rhythm for brushing.

The significant correlation of X-range between self-brushing and caregivers' brushing was recognized in both male and female. Though the participants in this study were dental professionals, if general people have similar tendencies, there is a possibility that giving the proper instructions for self-brushing in clinics will improve the technique of caregivers' brushing vice versa. Elderly and people with disabilities who need caregivers' brushing often find it difficult to visit dental clinics. There are few opportunities for dental professionals to instruct brushing directly, thus, demonstrating caregivers' brushing methods to nursing staff and family members instead as mentioned above might be very useful.

In reality, measuring brushing forces is usually difficult at clinics, thus the emphasis on tooth brushing instructions is often placed in brushing techniques. However, from current results, it was suggested that more attention should be paid to the brushing force. On the other hand, Annette, et al. [27] pointed out that brushing forces prior and after instructions of the brushing technique were not significantly different. Although to demonstrate and improve brushing force is certainly challenging, the system used in this study can monitor brushing force easily at clinics. Therefore, by using this device, we will be able to evaluate not only individual brushing characteristics but also changes of motion and force after giving proper tooth brushing instructions in the near future.

Oral hygiene education is not only the transfer of knowledge, but also must take into consideration personal habits and skills [20]. With more practical tooth brushing instructions, it is expected that caregivers who are not dental professionals can confidently perform caregivers' brushing, and the oral environment of persons who need care will be improved.

\section{Conclusion}

We evaluated the differences of brushing motion including force, between self-brushing and caregivers' brushing and focusing on the gender differences. Concerning self-brushing, gender difference was significant in cycle duration, buccal-lingual motion and brushing force, whereas for caregivers' brushing, a significant difference was observed only in the brushing force. In addition, the brushing force during caregivers' brushing was significantly greater than that of self-brushing on both genders. The significant intra-individual correlation of X-range between self-brushing and caregivers' brushing was recognized in both male and female.

In this study, dental professionals were selected as participants to research the typical caregivers' brushing. Further investigation on the actual caregivers is required to improve the oral hygiene status of the caretakers.

\section{Conflicts of interest}

The authors declare that they have no conflict of interests.

\section{References}

1. Telishevesky YS, Levin L, Ashkenazi M (2012) Assessment of parental tooth-brushing following instruction with single-headed and triple-headed toothbrushes. Pediatr Dent 34: 331-336. [Crossref]

2. Damle SG, Patil A, Jain S, Damle D, Chopal N (2014) Effectiveness of supervised toothbrushing and oral health education in improving oral hygiene status and practices of urban and rural school children: A comparative study. J Int Soc Prev Community Dent 4: 175-181. [Crossref]
3. Rodakowska E, Kierklo A, JamioÅ,kowski J (2016) Self-reported oral health behaviour among scandinavian and polish medical students studying in Poland. Cent Eur J Public Health 24: 68-75. [Crossref]

4. Kawamura M, Takase N, Sasahara H, Okada M (2008) Teenagers' oral health attitudes and behavior in Japan: comparison by sex and age group. J Oral Sci 50: 167-174 [Crossref]

5. Kim KD, Jeong JS, Lee HN, Gu Y, Kim KS, et al. (2015) Efficacy of computerassisted, 3D motion-capture toothbrushing instruction. Clin Oral Investig 19: 13891394. [Crossref]

6. Tosaka Y, Nakakura-Ohshima K, Murakami N, Ishii R, Saitoh I, et al. (2014) Analysis of tooth brushing cycles. Clin Oral Investig 18: 2045-2053. [Crossref]

7. Graetz C, Bielfeldt J, Wolff L, Springer C, El-Sayed KM, et al. (2013) Toothbrushing education via a smart software visualization system. J Periodontol 84: 186-195. [Crossref]

8. Inada E, Saitoh I, Yu Y, Tomiyama D, Murakami D, et al. (2015) Quantitative evaluation of toothbrush and arm-joint motion during tooth brushing. Clin Oral Investig 19: 1451-1462. [Crossref]

9. Lang T, Staufer S, Jennes B, Gaengler P (2014) Clinical validation of robot simulation of toothbrushing--comparative plaque removal efficacy. BMC Oral Health 14: 82. [Crossref]

10. Inada E, Saitoh I, Hayasaki H, Iwase Y, Kubota N, et al. (2012) Comparison of normal permanent and primary dentition sagittal tooth-crown inclinations of Japanese females. Cranio 30: 41-51. [Crossref]

11. Minihan PM, Morgan JP, Park A, Yantsides KE, Nobles CJ, et al. (2014) At-home oral care for adults with developmental disabilities: a survey of caregivers. J Am Dent Assoc 145: 1018-1025. [Crossref]

12. Elison S, Norgate S, Dugdill L, Pine C (2014) Maternally perceived barriers to and facilitators of establishing and maintaining tooth-brushing routines with infants and preschoolers. Int J Environ Res Public Health 11: 6808-6826. [Crossref]

13. Shyama M, Al-Mutawa SA, Honkala S, Honkala E (2003) Supervised toothbrushing and oral health education program in Kuwait for children and young adults with Down syndrome. Spec Care Dentist 23(3): 94-99. [Crossref]

14. Dieguez-Perez M, Nova-Garcia MJ, Mourelle-Martinez MR, Bartolome-Villar B (2016) Oral health in children with physical (Cerebral Palsy) and intellectual (Down Syndrome) disabilities: Systematic review I. J Clin Exp Dent 8: e337-343. [Crossref]

15. De Visschere LM, van der Putten GJ, Vanobbergen JN, Schols JM, de Baat C; Dutch Association of Nursing Home Physicians (2011) An oral health care guideline for institutionalised older people. Gerodontology 28: 307-310. [Crossref]

16. Garrido UC, Romo OF, Espinoza SI, Medics SD (2012) Oral health practices and beliefs among caregivers of the dependent elderly. Gerodontology 29: e742-747. [Crossref]

17. Kandelman D, Petersen PE, Ueda H (2008) Oral health, general health, and quality of life in older people. Spec Care Dentist 28: 224-236. [Crossref]

18. Forsell M, Kullberg E, Hoogstraate J, Johansson O, Sjögren P (2011) An evidencebased oral hygiene education program for nursing staff. Nurse Educ Pract 11: 256-259. [Crossref]

19. Kullberg E, Forsell M, Wedel P, Sjögren P, Johansson O, et al. (2009) Dental hygiene education for nursing staff. Geriatr Nurs 30: 329-333. [Crossref]

20. Ganss C, Schlueter N, Preiss S, Klimek J (2009) Tooth brushing habits in uninstructed adults--frequency, technique, duration and force. Clin Oral Investig 13: 203-208. [Crossref]

21. McConnell ES, Lekan D, Hebert C, Leatherwood L (2007) Academic-practice partnerships to promote evidence-based practice in long-term care: oral hygiene care practices as an exemplar. Nurs Outlook 55: 95-105. [Crossref]

22. Adams R (1996) Qualified nurses lack adequate knowledge related to oral health resulting in inadequate oral care of patients on medical wards. $J$ Adv Nurs 24: 552-560. [Crossref]

23. Frenkel H, Harvey I, Newcombe RG (2000) Oral health care among nursing home residents in Avon. Gerodontology 17: 33-38. [Crossref]

24. Lindqvist L, Seleskog B, Wardh I, von Bültzingslöwen I (2013) Oral care perspectives of professionals in nursing homes for the elderly. Int J Dent Hyg 11 : 298-305. [Crossref] 
25. Kobayashi Y, Hobara H, Heldoorn TA, Kouchi M, Mochimaru M (2016) Ageindependent and age-dependent sex differences in gait pattern determined by principal component analysis. Gait Posture 46: 11-17. [Crossref]

26. Lee DY, Seo SG, Kim EJ, Kim SJ, Lee KM, Chop IH (2016) Inter-segmental motions of the foot in healthy adults. Gender difference. J Orthop Sci 21: 804-809. [Crossref]

27. Wiegand A, Burkhard JPM, Eggmann F, Attin T (2013) Brushing force of manual and sonic toothbrushes affects dental hard tissue abrasion. Clin Oral Investig 17: 815-22. [Crossref]

28. Phaneuf EA, Harrington JH, Dale PP, Shklar G (1962) Automatic toothbrush: a new reciprocating action. J Am Dent Assoc 65: 12-25. [Crossref]
29. Burgett FG, Ash MM Jr (1974) Comparative study of the pressure of brushing with three types of toothbrushes. J Periodontol 45: 410-413. [Crossref]

30. Akgül HM, Akgül N, Karaoglanoglu S, Ozdabak N (2003) A survey of the correspondence between abrasions and tooth brushing habits in Erzurum, Turkey. Int Dent J 53: 491-495. [Crossref]

31. Sadaf D, Ahmad Z (2014) Role of brushing and occlusal forces in non-carious cervical lesions (NCCL). Int J Biomed Sci 10: 265-268. [Crossref]

32. Uenoyama A, Inada J (1990) Muscle activities in the hand and arm during tooth brushing and the regulation of brushing movements by oral sensory perception. $J$ Osaka Dent Univ 24: 87-120. [Crossref]

Copyright: $@ 2018$ Hanasaki M. This is an open-access article distributed under the terms of the Creative Commons Attribution License, which permits unrestricted use, distribution, and reproduction in any medium, provided the original author and source are credited. 